\title{
Comparison of the Efficacy of Two Brands of Triptorelin (Microrelin and Diphereline) in Reducing Prostate-Specific Antigen and Serum Testosterone in Prostate Cancer:A Double-Blinded Randomized Clinical Trial
}

\author{
Farid Fazeli ${ }^{1}$; Mohammad Reza Nowroozi ${ }^{1,}$; Mohsen Ayati ${ }^{1}$; Sahar Latifi ${ }^{2}$; Mohsen Taheri \\ Mahmoodi ${ }^{1}$; Abbas Norouzi Javidan ${ }^{2}$; Hassan Jamshidian ${ }^{1}$; Amir Arbab ${ }^{1}$ \\ ${ }^{1}$ Uro-Oncology Research Center, Tehran University of Medical Sciences, Tehran, IR Iran \\ ${ }^{2}$ Brain and Spinal Cord Injury Research Center, Neuroscience Institute, Tehran University of Medical Sciences, Tehran, IR Iran \\ ${ }^{*}$ Corresponding author: Mohammad Reza Nowroozi, Uro-Oncology Research Center, Tehran University of Medical Sciences, Tehran, IR Iran. Tel:+98-2166903063, Fax: +98-2166903063, \\ E-mail:mrnowroozi@tums.ac.ir
}

Received: January 18, 2015; Revised: February 19, 2015; Accepted: March 2, 2015

\begin{abstract}
Background: Gonadotropin-releasing hormone (GnRH) agonists initiate androgen deprivation in treating prostate cancer (PC). Triptorelin is a synthetic GnRH and many of its market brands such as Diphereline have been introduced so far.

Objectives: We compared the efficacy of a sustained-release formulation of Triptorelin (Microrelin), domestically produced in Iran, and compared it with Diphereline in a double-blinded randomized clinical trial.

Patients and Methods: Patients were randomly assigned to Group A (Microrelin S.R. 3.75 mg, Pooyesh Darou, Iran) and Group B (Diphereline S.R. 3.75 mg, IPSEN, France). Each patient received monthly intramuscular injections. Prostate-specific antigen (PSA) and circulatory testosterone were measured at baseline and after one, 3 , and 6 months.

Results: Each group contained 40 patients. In Group A, PSA was reduced from $75.78 \pm 72.43 \mathrm{ng} / \mathrm{mL}$ to $1.93 \pm 1.40 \mathrm{ng} / \mathrm{mL}$ after $6 \mathrm{months}$ and testosterone was reduced from $3.50 \pm 1.12 \mathrm{nmol} / \mathrm{L}$ to $0.81 \pm 0.05 \mathrm{nmol} / \mathrm{L}$. There was no significant difference between the efficacy of Microrelin and Diphereline. Two patients in the Microrelin Group and one patient in the Diphereline Group failed to reach medical castration (testosterone $<1.7 \mathrm{nmol} / \mathrm{L}$ ), which illustrates that the power of Microrelin and Dipherelin in initiating medical castration is about $95 \%$ and $97.5 \%$, respectively.

Conclusions: Our study showed that Microrelin is as effective as Diphereline in reducing PSA and testosterone and can be recommended to initiate medical castration in patients with PC.
\end{abstract}

Keywords: Prostate Cancer; Prostate-Specific Antigen; Testosterone; Gonadotropin-Releasing Hormone

\section{Background}

Prostate cancer (PC) is one of the most frequently occurring cancers among men (1), and its incidence in Iran has been estimated at approximately 5.1 per 100000 person-years (2). Since PC is hormone-dependent, the suppression of circulatory testosterone has become a major palliative treatment in patients with advanced PC (3). Androgen deprivation is mainly achieved by two methods of castration: surgical (bilateral orchiectomy) or medical (administration of gonadotropin-releasing hormone [GnRH] agonists/antagonists, anti-androgens, or estrogen therapy) $(4,5)$. Triptorelin is a synthetic GnRH analogue which initially stimulates the pituitary gland, but its continuous administration inhibits the secretion of gonadotropins as a result of receptor desensitization and/or downregulation. It has been shown that Triptorelin is a well-tolerated medication and is able to maintain the castration for the treatment of advanced PC (6). Prostate-specific antigen (PSA) is a biomarker routinely used for the early detection of PC and also monitoring the response to the treatment $(7,8)$. Although PSA is not a cancer-specific marker and can be elevated in many other conditions such as benign hyperplasia $(9,10)$, it is still the most commonly used biomarker to screen PC.

Among medications that contain Triptorelin pamoate, Diphereline is a long-acting GnRH agonist which is commonly used. An Iranian biomedicine corporation, Pooyesh Darou, has designed a Triptorelin sustained-release formulation named Microrelin. This product contains $3.75 \mathrm{mg}$ of Triptorelin and allows the continuous release of the drug over 30 days so that $3.75 \mathrm{mg}$ of Triptorelin peptide correspond to a maximum dose of 0.100 $\mathrm{mg} /$ day plus a $25 \%$ excess.

\section{Objectives}

In the present study, we tried to evaluate and compare

Copyright (C) 2015, Nephrology and Urology Research Center. This is an open-access article distributed under the terms of the Creative Commons Attribution-NonCommercial 4.0 International License (http://creativecommons.org/licenses/by-nc/4.0/) which permits copy and redistribute the material just in noncommercial usages, provided the original work is properly cited 
the efficacy of the commonly used brands of Triptorelin, namely Diphereline S.R. (3.75 mg, IPSEN, France) with Microrelin S.R. (3.75 mg Pooyesh Darou, Iran), in reducing circulatory testosterone and PSA among patients with advanced PC. The main purpose of this study was to find out whether Microrelin has the similar acceptable efficacy in reducing testosterone and PSA in comparison with the commonly used brands such as Diphereline.

\section{Patients and Methods}

\subsection{Study Design and Participants}

This investigation is a double-blinded randomized clinical trial (Number: IRCT201310229819N3). Participants were patients with advanced PC who were referred to the urology clinic. Patients who had metastatic PC were included in this trial. The exclusion criteria were previous history of other malignancies; endocrine disorders affecting the hypothalamus-pituitary axis or pituitarytarget organ axis; hypo-or hyperthyroidism; previous history of coagulopathy; and consumption of special medications such as glucocorticoids, hormones (including other GnRH agonists), thyroid hormones, anticonvulsive drugs, and Heparin or Warfarin. Data were collected from September 2012 to March 2013. Before enrollment, adequate information about the trial was given to each patient. Participation in this trial was voluntary. The study was approved by the Ethics Committee of Tehran University of Medical Sciences. The participants were divided into two groups by using the permuted balanced block randomization method. Group A received $3.75 \mathrm{mg}$ of Microrelin S.R. (Pooyesh Darou, Iran) and Group B received $3.75 \mathrm{mg}$ of Diphereline S.R. (IPSEN, France) through intramuscular injections administered every 28 days during 6 months of treatment.

\subsection{Intervention}

Microrelin $3.75 \mathrm{mg}$, a Triptorelin sustained-release formulation, was provided by Pooyesh Darou Corporation in collaboration with the International Centre for Genetic Engineering and Biotechnology (ICGEB) in Italy. Group A received $3.75 \mathrm{mg}$ of Microrelin S.R. intramuscularly every 28 days. Each patient received 6 injections.

Diphereline (Triptorelin embonate) has two forms of $3.75 \mathrm{mg}$, which is injected every month, and $11.25 \mathrm{mg}$, which is injected every 3 months. In this trial, monthly injections of Diphereline $3.75 \mathrm{mg}$ (IPSEN, France) were administered to the patients in Group B. Each patient received 6 injections during 6 months of treatment.

\subsection{Measurements}

Blood samples were taken under antiseptic conditions from the antecubital vein. Serum PSA and testosterone were measured at baseline and then after one, 3 , and 6 months in both groups. PSA was measured in the laboratory using the (f-PSA) Human ELISA Kit, which is a Sandwich Enzyme-Linked Immunosorbent Assay kit designed for the quantitative measurement of human PSA and has a detection sensitivity of $0.1 \mathrm{ng} / \mathrm{mL}$. A Testosterone ELIZA Kit, with a detection sensitivity of $0.07 \mathrm{ng} / \mathrm{dL}$, was used to measure circulatory testosterone.

The assessment of the prognosis of PC was performed by measuring the Gleason score. The Gleason Grading System is used to evaluate the prognosis of men with PC. This score is given to PC based upon its microscopic appearance (11). The Gleason scores range from 2 to 10, with 2 representing the best-differentiated tumors and 10 the least-differentiated tumors. The Gleason score is described by two grades which are added to yield the Gleason sum. The first number is the primary grade assigned to the dominant pattern of the tumor (has to be $>50 \%$ of the total pattern seen), and the second number is the secondary grade assigned to the next-most frequent pattern (has to be $<50 \%$, but at least $5 \%$, of the pattern of the total cancer observed). Pattern I indicates well-differentiated carcinoma, pattern II shows moderately differentiated carcinoma, pattern III corresponds to a moderately differentiated carcinoma with and an infiltrative pattern, pattern IV corresponds to a poorly differentiated carcinoma, and finally, pattern $\mathrm{V}$ illustrates anaplastic carcinoma (11). More recently, an investigation of the Johns Hopkins Radical Prostatectomy Database (1982 - 2011) led to the proposed reporting of the Gleason grades and prognostic grade groups as: Gleason score $\leq 6$ (prognostic grade Group I); Gleason score $=3$ $+4=7$ (prognostic grade Group II); Gleason score $=4+3$ $=7$ (prognostic grade Group III); Gleason score $=4+4=8$ (prognostic grade Group IV); and Gleason scores = 9-10 (prognostic grade Group V) (12). Research shows that the Gleason score of 8 , which contains a primary or secondary pattern of $5(3+5,5+3)$, has similar prognostic outcomes with the Gleason scores of 9 - 10 (grade Group V) (13). Patients with the Gleason score $<6$ have a good prognosis, and metastasis and disease-specific death are uncommon among these patients (14).

\subsection{Statistical Analysis}

All the statistical analyses were performed using SPSS software, version 18.0 (SPSS Inc., Chicago IL, USA). The categorical values are reported by percentages, and the continuous data are expressed by mean \pm standard deviation (SD). The one-way analysis of variance (ANOVA) with test for linearity was used to compare the means between the groups. The Pearson chi-square test was utilized to compare the categorical data, and the Independent t-test with a confidence interval of $95 \%$ was employed to compare the quantitative value of both groups before and after intervention with each other. A P $<0.05$ was considered statistically significant. 


\section{Results}

\subsection{Baseline Characteristics}

Eighty male patients with metastatic PC were included in this investigation and were divided randomly into two groups. Each group contained 40 participants. The mean age in Group A was $72.5 \pm 6.58$ years (range $=55$ - 86) and in Group B was $72.45 \pm 5.48$ years (range $=62$ $82)$. There was no significant difference in the age of the patients between the two groups $(P=0.97)$. Among the patients in Group A, 6 (15\%) participants had prognostic grade Group II (Gleason score $=3+4$ ) and 13 (32.5\%) patients had prognostic grade Group III (Gleason score $=$ $4+3)$. Eighteen (45\%) patients in Group A had a Gleason score higher than 8 . Five (12.5\%) participants in Group B had prognostic grade Group II and 12 (30\%) patients were in grade III. Table 1 illustrates the baseline characteristics of these patients. The baseline mean concentration of PSA in Group A was $75.78 \pm 72.43 \mathrm{ng} / \mathrm{mL}$ and in Group B was $75.48 \pm 63.47 \mathrm{ng} / \mathrm{mL}$. The mean concentration of serum testosterone was $3.50 \pm 1.12 \mathrm{nmol} / \mathrm{L}$ in Group A and $3.62 \pm 0.80 \mathrm{nmol} / \mathrm{L}$ in Group B. There was no significant difference in the baseline levels of PSA and circulatory testosterone between the two groups ( $\mathrm{P}=0.98$ and $\mathrm{P}=0.57$ for PSA and testosterone, respectively) (Table 1$)$.
4.2. Comparison of the Efficacy of Microrelin and Diphereline on Prostate-Specific Antigen and Circulatory Testosterone

The effects of Microrelin and Diphereline on serum PSA and testosterone were assessed in 3 stages. In stage I, PSA and testosterone were measured after one month, and the difference between these values and the baseline concentrations was calculated. After 3 months (stage II), the circulatory levels of PSA and testosterone were measured again, and the amount of the reduction in their concentrations compared with the baseline values was calculated. In stage III, the amount of change from the baseline values was calculated after 6 months. Tables 2 and 3 show the outcomes of treatments in both groups through all the stages of this trial. PSA in Group A (Microrelin Group) was reduced from $75.78 \pm 72.43 \mathrm{ng} / \mathrm{mL}$ at baseline to 36.17 $\pm 35.10 \mathrm{ng} / \mathrm{mL}$ after one month. After 3 months, its concentration was further decreased and reached $9.66 \pm 8.92$ $\mathrm{ng} / \mathrm{mL}$ and after 6 months of treatment with Microrelin, the PSA level was reduced to $1.93 \pm 1.40 \mathrm{ng} / \mathrm{mL}$. In Group B, PSA was reduced to $33.52 \pm 25.88 \mathrm{ng} / \mathrm{mL}$ in stage I (mean difference $=-41.95$ ), $9.20 \pm 5.41 \mathrm{ng} / \mathrm{mL}$ in stage II (mean difference $=-66.27$ ), and $1.95 \pm 1.39 \mathrm{ng} / \mathrm{mL}$ (mean difference $=-73.53$ ) in stage III. There was no significant difference between the efficacy of Microrelin and Diphereline in reducing PSA ( $\mathrm{P}=0.85, \mathrm{P}=0.99$, and $\mathrm{P}=0.98$ in stages I, II, and III, respectively) (Table 2 ).

\begin{tabular}{|c|c|c|c|c|c|}
\hline Category & Group A & Group A & Group B & Group B & P Value \\
\hline Age, $y$ & - & $72.5(6.58)$ & - & $72.45(5.48)$ & $0.97^{\mathrm{C}}$ \\
\hline Prognostic grade group & & & & & $0.73^{d}$ \\
\hline Grade I (Gleason score < 6) & $3(7.5 \%)$ & - & $3(7.5 \%)$ & - & \\
\hline Grade II (Gleason score:3+4) & $6(15 \%)$ & - & $5(12.5 \%)$ & - & \\
\hline Grade III (Gleason score: $4+3$ ) & $13(32.5 \%)$ & - & $12(30 \%)$ & - & \\
\hline Grade IV(Gleason score: 8) & $12(30 \%)$ & - & $17(42.5 \%)$ & - & \\
\hline Grade V(Gleason score: 9,10) & $6(15 \%)$ & - & $3(7.5 \%)$ & - & \\
\hline Prostate-specific antigen, $\mathrm{ng} / \mathrm{mL}$ & - & $75.78(72.43)$ & - & $75.48(63.47)$ & $0.98^{\mathrm{C}}$ \\
\hline Testosterone, nmol/L & - & $3.50(1.12)$ & - & $3.62(0.80)$ & $0.57^{\mathrm{C}}$ \\
\hline
\end{tabular}

\footnotetext{
a Data are presented as Frequency (\%).

b Data are presented as Mean (SD).

c P values stand for the comparison of means between the groups with the one-way analysis of variance (ANOVA).

$\mathrm{d}$ P values stand for the Pearson chi-square test.
}

\begin{tabular}{|c|c|c|c|c|c|c|c|c|c|}
\hline & $\begin{array}{l}\text { PSA after one } \\
\text { Month, ng/mL }\end{array}$ & $\begin{array}{c}\text { Mean Difference } \\
\text { Stage I }\end{array}$ & PValue & $\begin{array}{c}\text { PSA after } 3 \\
\text { Months, ng/mL }\end{array}$ & $\begin{array}{c}\text { Mean Difference } \\
\text { Stage II }\end{array}$ & PValue & $\begin{array}{c}\text { PSA after } 6 \\
\text { Months, ng/mL }\end{array}$ & $\begin{array}{c}\text { Mean Difference } \\
\text { Stage III }\end{array}$ & P Value \\
\hline Groups & & & 0.85 & & & 0.99 & & & 0.98 \\
\hline Group A & $36.17(35.10)$ & -39.61 & & $9.66(8.92)$ & -66.12 & & $1.93(1.40)$ & -73.85 & \\
\hline Group B & $33.52(25.88)$ & -41.95 & & $9.20(5.41)$ & -66.27 & & $1.95(1.39)$ & -73.53 & \\
\hline
\end{tabular}

a Data are presented with mean values (standard deviation)

b Pvalues stand for the comparison of the mean differences in each stage between Group A and Group B with the one-way analysis of variance (ANOVA). 
Fazeli F et al.

\begin{tabular}{|c|c|c|c|c|c|c|c|c|c|}
\hline & $\begin{array}{c}\text { Testosterone after } \\
\text { One Month, nmol/L }\end{array}$ & $\begin{array}{l}\text { Mean Difference } \\
\text { Stage I }\end{array}$ & P Value & $\begin{array}{c}\text { Testosterone after } \\
3 \text { Months, nmol/L }\end{array}$ & $\begin{array}{c}\text { Mean Difference } \\
\text { Stage II }\end{array}$ & $\begin{array}{c}P \\
\text { Value }\end{array}$ & $\begin{array}{l}\text { Testosterone after } \\
6 \text { Months, nmol/L }\end{array}$ & $\begin{array}{c}\text { Mean Difference } \\
\text { Stage III }\end{array}$ & $\begin{array}{c}\mathbf{P} \\
\text { Value }\end{array}$ \\
\hline Groups & & & 0.51 & & & 0.78 & & & 0.77 \\
\hline Group A & $1.58(0.68)$ & -1.92 & & $1.11(0.61)$ & -2.38 & & $0.81(0.05)$ & -2.68 & \\
\hline Group B & $1.85(0.46)$ & -1.77 & & $1.30(0.42)$ & -2.32 & & $1.12(1.0)$ & -2.60 & \\
\hline
\end{tabular}

a Data are presented with mean values (standard deviation).

$\mathrm{b}$ Pvalues stand for the comparison of the mean differences in each stage between Group A and Group B with the one-way analysis of variance (ANOVA).

Circulatory testosterone was reduced from $3.50 \pm 1.12$ $\mathrm{nmol} / \mathrm{L}$ to $1.58 \pm 0.68 \mathrm{nmol} / \mathrm{L}$ after one month and to $0.81 \pm$ $0.05 \mathrm{nmol} / \mathrm{L}$ after 6 months in Group A. In Group B, testosterone decreased to $1.85 \pm 0.46 \mathrm{nmol} / \mathrm{L}$ at stage I and $1.12 \pm$ $1.0 \mathrm{nmol} / \mathrm{L}$ at stage III. No significant difference between the efficacy of Microrelin and Diphereline could be detected in reducing the testosterone level $(\mathrm{P}=0.51, \mathrm{P}=0.78$, and $\mathrm{P}=0.77$ for stages I, II, and III, respectively) (Table 3 ).

The level of PSA at baseline was significantly correlated with the amount of change in the PSA concentration in both groups. In fact, higher levels of PSA at baseline were associated with a higher reduction in PSA at all the stages of the trial $(\mathrm{P}<0.0001, \mathrm{r}=0.87 ; \mathrm{P}<0.0001, \mathrm{r}=0.99$; and $\mathrm{P}$ $<0.0001, r=0.99$ for the mean reduced amount of PSA at stages I, II, and III, respectively, in Group A and P <0.0001, $r=0.92 ; \mathrm{P}<0.0001, \mathrm{r}=99$; and $\mathrm{P}<0.0001, \mathrm{r}=0.99$ for the mean reduced amount of PSA at stages I, II, and III, respectively, in Group B). The PSA concentration was significantly higher in the patients in the prognostic grade Group V (Gleason scores of 9 and 10) $(\mathrm{P}<0.0001)$. As was expected, since the patients with the Gleason scores of 9 and 10 had the highest baseline concentration of PSA, the highest amount of reduction in PSA was observed among these patients. However, this significant reduction in PSA among the patients in the prognostic grade Group V in comparison with the other grade groups was only detected after 3 months of intervention in Group A ( $\mathrm{P}=0.20, \mathrm{P}$ $=0.003$, and $\mathrm{P}=0.004$ at stages I, II, and III, respectively), while this reduction in Group $\mathrm{B}$ was significant from stage $\mathrm{I}(\mathrm{P}=0.03, \mathrm{P}=0.006$, and $\mathrm{P}=0.006$ for stages $\mathrm{I}$, II and III, respectively). It shows that although in both groups the trend was toward a higher reduction in PSA among the patients with a higher baseline PSA (Gleason scores of 9 and 10), among the patients who received Diphereline, this difference could be observed after one month but among those who received Microrelin, this difference became significant first 3 months after treatment.

The level of circulatory testosterone at baseline and before any intervention was positively associated with the amount of the reduction in testosterone in all the stages of the trial $(\mathrm{P}<0.0001, \mathrm{r}=0.83 ; \mathrm{P}<0.0001, \mathrm{r}=0.87$; and $\mathrm{P}<0.0001, \mathrm{r}=0.90$ at stages I, II, and III, respectively, in Group A and $\mathrm{P}<0.0001, \mathrm{r}=0.82 ; \mathrm{P}<0.0001, \mathrm{r}=0.87$; and $\mathrm{P}<0.0001, \mathrm{r}=0.60$ at stages I, II, and III, respectively, in Group B).

\section{Discussion}

Triptorelin is a GnRH analogue that has been shown to be effective in the initiation and maintenance of medical castration in patients with advanced PC (15-17). Triptorelin is marketed under many brand names, including Decapeptyl (IPSEN), Diphereline, and Gonapeptyl. In the United States, it also can be found under the brand name of Trelstar. Here in Iran, a biomedicine corporation (Pooyesh Darou) has designed a sustained-release formulation of Triptorelin under the marketing name of Microrelin. In the present study, we assessed the efficacy of this product to determine whether it had the similar efficacy compared with the commonly used medications such as Diphereline. Our study illustrated that Microrelin has similar efficacy by comparison with Diphereline in reducing PSA and circulatory testosterone. Our results show that this product is an effective medication in initiating and maintaining medical castration, which is an important therapeutic goal in patients with advanced PC.

GnRH agonists mediate their action via the chronic stimulation of the pituitary gland and, therefore, downregulation of GnRH receptors, inhibiting the release of luteinizing hormone (18). The administration of these medications initially increases the testosterone level but after 2 - 4 weeks reduces its concentration to castration levels (19). Previously, the castration level of testosterone by medical therapy was considered below $50 \mathrm{ng} / \mathrm{dL}$ (5 ng/mL, $1.7 \mathrm{nmol} / \mathrm{L}$ ) (20-22), but Dason et al. (23) in 2013 defined a new threshold for the castration level $(<3.2 \mathrm{ng} /$ $\mathrm{mL},<1.1 \mathrm{nmol} / \mathrm{L})$. In the present study, when considering the previous threshold of testosterone, 2 subjects in the Microrelin Group and one subject in the Diphereline Group failed to reach medical castration after 6 months. This finding showed that Microrelin had the potential to initiate medical castration in $95 \%$ of our patients, while this level was $97.5 \%$ when using Dipherelin. Our analysis showed no significant difference in the power of these two medications in initiating medical castrations, which illustrates that the Iranian Triptorelin product, which is a sustained-release formulation, is an efficient medication to decrease the testosterone level below castration levels. According to the guideline of The European Association of Urology (EAU), castration-resistant PC is defined by failure to achieve medical castration illustrated by 3 consecutive rises in PSA or PSA progression despite hor- 
Fazeli F et al.

monal manipulations (24). In our study, none of the patients in both groups showed castration-resistant PC. In this regard, previous studies have shown that the efficacy of the GnRH agonist (e.g. Leuprolide) and the GnRH antagonist (e.g. Degarelix) is similar in suppressing PSA and testosterone levels among patients with metastatic disease (25). Moreover, Shore et al. (26) illustrated that the administration of intramuscular Triptorelin was associated with less post-injection burning sensation, soreness, discomfort, bother by redness, itching, hardening of the injection site, and anxiety in comparison with the subcutaneous injection of Leuprolide in their study population. According to these studies that show the similar efficacy of GnRH agonists in comparison with GnRH antagonists and also the fewer complications of Triptorelin in comparison with other GnRH agonists (25, $26)$, the administration of Triptorelin in order to achieve androgen deprivation is recommended. We did not assess the complications of Microrelin, which is the most important limitation of the present study. Our investigation confirms that Microrelin, which is produced in Iran, is as effective as other Triptorelin brands such as Diphereline. Nevertheless, further investigations should clarify the probable complications of this medication.

The current study compared the efficacy of two brands of Triptorelin (Microrelin and Diphereline) in reducing circulatory PSA and testosterone levels. Our data showed the similar efficacy of Microrelin in comparison with Diphereline in reducing PSA and testosterone concentrations after one, 3, and 6 months of intervention. Microrelin initiated medical castration in $95 \%$ of our patients, whereas this amount was $97.5 \%$ by prescribing Dipherelin.

\section{Acknowledgements}

We would like to thank all the staff that cooperated with the process of data collection.

\section{Financial Disclosure}

All authors declare that they have no conflict of interest in any terms and conditions related to this investigation.

\section{Funding/Support}

This study was financially supported by Tehran University of Medical Sciences.

\section{References}

1. Siegel R, Naishadham D, Jemal A. Cancer statistics, 2013. CA Cancer J Clin. 2013;63(1):11-30.

2. Sadjadi A, Nooraie M, Ghorbani A, Alimohammadian M, Zahedi MJ, Darvish-Moghadam S, et al. The incidence of prostate cancer in Iran: results of a population-based cancer registry. Arch Iran Med. 2007;10(4):481-5.

3. Huggins $C$, Hodges CV. Studies on prostatic cancer: I. The effect of castration, of estrogen and of androgen injection on serum phosphatases in metastatic carcinoma of the prostate. 1941. J Urol. 2002;168(1):9-12.
4. Sharifi N, Gulley JL, Dahut WL. An update on androgen deprivation therapy for prostate cancer. Endocr Relat Cancer. 2010;17(4):R305-15.

5. Damber J-E, Aus G. Prostate cancer. Lancet. 2008;371(9625):1710-21.

6. Lundstrom EA, Rencken RK, van Wyk JH, Coetzee LJ, Bahlmann JC, Reif S, et al. Triptorelin 6-month formulation in the management of patients with locally advanced and metastatic prostate cancer: an open-label, non-comparative, multicentre, phase III study. Clin Drug Investig. 2009;29(12):757-65.

7. Pezaro C, Woo HH, Davis ID. Prostate cancer: measuring PSA. Intern Med J. 2014;44(5):433-40.

8. Verma A, St Onge J, Dhillon K, Chorneyko A. PSA density improves prediction of prostate cancer. Can JUrol. 2014;21(3):7312-21.

9. Gao ZW, Liu G, Sheng BW. [Changes of serum total PSA and free PSA in patients with prostate carcinoma and benign prostate hyperplasia]. Ai Zheng. 2004;23(6):701-3.

10. Tuppin P, Samson S, Fagot-Campagna A, Lukacs B, Alla F, Allemand $\mathrm{H}$, et al. [PSA testing, biopsy and cancer and benign prostate hyperplasia in France]. Prog Urol. 2014;24(9):572-80.

11. Epstein JI, Allsbrook WJ, Amin MB, Egevad LL, Isup Grading Committee. The 2005 International Society of Urological Pathology (ISUP) Consensus Conference on Gleason Grading of Prostatic Carcinoma. Am J Surg Pathol. 2005;29(9):1228-42.

12. Pierorazio PM, Walsh PC, Partin AW, Epstein JI. Prognostic Gleason grade grouping: data based on the modified Gleason scoring system. BJU Int. 2013;111(5):753-60.

13. Turker P, Bas E, Bozkurt S, Gunlusoy B, Sezgin A, Postaci H, et al. Presence of high grade tertiary Gleason pattern upgrades the Gleason sum score and is inversely associated with biochemical recurrence-free survival. Urol Oncol. 2013;31(1):93-8.

14. Kweldam CF, Wildhagen MF, Bangma CH, van Leenders GJ. Disease-specific death and metastasis do not occur in patients with Gleason score $<1=6$ at radical prostatectomy. BJU Int. 2014.

15. Ploussard G, Mongiat-Artus P. Triptorelin in the management of prostate cancer. Future Oncol. 2013;9(1):93-102.

16. Kao CC, Chang YH, Wu T, Sun GH, Yu DS, Chang SY, et al. Open, multi-center, phase IV study to assess the efficacy and tolerability of triptorelin in Taiwanese patients with advanced prostate cancer. J Chin Med Assoc. 2012;75(6):255-61.

17. Whelan P. Triptorelin embonate: a 6-month formulation for prostate cancer. Expert Opin Pharmacother. 2010;11(17):2929-32.

18. Limonta P, Montagnani Marelli M, Moretti RM. LHRH analogues as anticancer agents: pituitary and extrapituitary sites of action. Expert Opin Investig Drugs. 2001;10(4):709-20.

19. Schally AV. Luteinizing hormone-releasing hormone analogs: their impact on the control of tumorigenesis. Peptides. 1999;20(10):1247-62.

20. Wheeler MJ, D'Souza A, Matadeen J, Croos P. Ciba Corning ACS:180 testosterone assay evaluated. Clin Chem.1996;42(9):1445-9.

21. Oefelein MG, Feng A, Scolieri MJ, Ricchiutti D, Resnick MI. Reassessment of the definition of castrate levels of testosterone: implications for clinical decision making. Urology. 2000;56(6):1021-4.

22. Morote J, Orsola A, Planas J, Trilla E, Raventos CX, Cecchini L, et al. Redefining clinically significant castration levels in patients with prostate cancer receiving continuous androgen deprivation therapy. J Urol. 2007;178(4 Pt 1):1290-5.

23. Dason S, Allard CB, Tong J, Shayegan B. Defining a new testosterone threshold for medical castration: Results from a prospective cohort series. Can Urol Assoc J. 2013;7(5-6):E263-7.

24. Heidenreich A, Bastian PJ, Bellmunt J, Bolla M, Joniau S, van der Kwast T, et al. EAU guidelines on prostate cancer. Part II: Treatment of advanced, relapsing, and castration-resistant prostate cancer. Eur Urol. 2014;65(2):467-79.

25. Klotz L, Boccon-Gibod L, Shore ND, Andreou C, Persson BE, Cantor P, et al. The efficacy and safety of degarelix: a 12-month, comparative, randomized, open-label, parallel-group phase III study in patients with prostate cancer. BJU Int. 2008;102(11):1531-8.

26. Shore ND, Sieber P, Schimke L, Perzin A, Olsen S. Comparison of tolerability and adverse events following treatment with two GnRH agonists in patients with advanced prostate cancer. Urol Nurs. 2013;33(5):236-44. 